\title{
Neocoelindroma, gênero novo de Neocoelidiinae (Hemiptera, Auchenorrhyncha, Cicadellidae) da Região Neotropical ${ }^{1}$
}

\author{
Ana Paula Marques-Costa ${ }^{2} \&$ Rodney R. Cavichioli ${ }^{2}$ \\ ${ }^{1}$ Contribuição número 1676 do Departamento de Zoologia, Universidade Federal do Paraná. \\ 2 Programa de Pós-graduação em Entomologia, Departamento de Zoologia, Universidade Federal do Paraná. \\ Caixa Postal 19020,81531-980 Curitiba, Paraná,Brasil.E-mail: apcm@ufpr.br; cavich@ufpr.br
}

\begin{abstract}
Neocoelindroma, a new genus of Neocoelidiinae (Hemiptera, Auchenorrhyncha, Cicadellidae) from the Neotropical Region. A new genus of Neocoelidiinae, Neocoelindroma gen. nov., and its type-species, Neocoelindroma nigricephala sp. nov., are described from Ecuador. This new genus has the external coloration similar to that of Coelindroma Kramer, 1967, but it can be distinguished from this and the other Neocoelidiinae genera by the features of the male genitalia and by the black color of the head in frontal view. Illustrations and the geographical distribution of the studied species are given.

KEY WORDS. Ecuador; geographical distribution; morphology; Neocoelindroma nigricephala sp. nov.; taxonomy.

RESUMO. Um gênero novo de Neocoelidiinae, Neocoelindroma gen. nov., e sua espécie-tipo, Neocoelindroma nigricephala sp. nov., são descritos do Equador. O novo gênero possui coloração externa semelhante à de Coelindroma Kramer, 1967, mas pode ser separado deste e dos demais gêneros de Neocoelidiinae pelas características da genitália masculina e pela coloração preta da cabeça em vista frontal. São fornecidas ilustrações e a distribuição geográfica da espécie estudada.
\end{abstract}

PALAVRAS-CHAVE. Distribuição geográfica; Equador; morfologia; Neocoelindroma nigricephala sp. nov.; taxonomia.

Neocoelidiinae compreende uma única tribo, Neocoelidiini, atualmente com 160 espécies em 26 gêneros (MARQUes-Costa \& CAVICHIOLI 2006b). A subfamília é principalmente neotropical, havendo apenas quatro gêneros com registros para a Região Neártica: Coelella DeLong, 1953, Neocoelidia Gillette \& Baker, 1895, Cocoelidia DeLong, 1953 e Neocoelidiana DeLong, 1953 (Nielson \& KNIGHT 2000).

A subfamília inclui cigarrinhas de tamanho pequeno a médio (5,0-12,0 mm), de coloração geral normalmente em tons pálidos, que podem ser identificadas pelo seguinte conjunto de características: cabeça projetada anteriormente, freqüentemente com carena marginal; coroa elevada e achatada entre os olhos; ocelos na margem anterior da cabeça ou próximos a esta; suturas frontogenais estendendo-se ou não até os ocelos; antenas extremamente longas, com escapo e pedicelo bem desenvolvidos; clípeo com ou sem intumescimento mediano ou tubérculo; mesotórax freqüentemente bem desenvolvido, a pleura estendendo-se até a região do esterno, dando aos neocelidiíneos um aspecto intumescido ventralmente; venação da asa anterior geralmente indistinta, exceto apicalmente; $\mathrm{R}_{4+5}$ e $\mathrm{M}_{1+2}$ da asa posterior geralmente confluentes pré-apicalmente.

DieTrich (2003) redescreveu a subfamília, redefinindo-a para englobar três gêneros antes pertencentes à Nirvaninae -
Krocodona Kramer, 1964 (com nova sinonímia, Krocobella Kramer, 1964), Krocozzota Kramer, 1964, e Krocarites Dietrich \& Vega, 1995 - e mais dois gêneros novos - Retrolidia e Krocolidia. Afirmou que apesar destes gêneros possuírem cabeça fortemente projetada anteriormente e lobos supra-antenais reduzidos, diferindo do conceito de Neocoelidiinae sensu KRAMER (1964), foram incluídos em Neocoelidiinae por exibirem algumas características comuns aos neocelidiíneos, prováveis sinapomorfias para a subfamília, tais como: valva subgenital (esternito VIII) do macho fusionado às placas subgenitais, mas articulada ao pigóforo; pigóforo com dente ou espinho posteroventral e asa posterior com as veias $\mathrm{R}_{4+5}$ e $\mathrm{M}_{1+2}$ confluentes.

Entretanto, não há estudos específicos sobre as relações filogenéticas entre os gêneros e espécies de Neocoelidiinae. Vários caracteres citados por DieTRIch (2004) são muito variáveis entre os gêneros da subfamília, e provavelmente não constituem sinapomorfias para o grupo. Faz-se necessário um estudo mais aprofundado, para uma melhor caracterização dos gêneros e para testar a monofilia da subfamília.

Este trabalho inclui a descrição de um gênero novo de Neocoelidiinae, Neocoelindroma gen. nov., e de uma espécie nova, N. nigricephala sp. nov. São fornecidas ilustrações e a distribuição geográfica da espécie estudada.

Revista Brasileira de Zoologia 24 (1): 233-237, março 2007 


\section{MATERIAL E MÉTODOS}

O material estudado pertence ao United States National Museum (USNM), Washington, D.C., Estados Unidos da América.

Para a análise das estruturas da genitália, seguiu-se a metodologia adotada por MARQUes-Costa \& CAVICHIOLI (2006a), exceto pelo que segue: a asa anterior foi ilustrada diretamente a partir do espécime-tipo, evitando assim, a remoção da asa do holótipo. O espécime foi identificado e descrito com o auxílio de microscópio estereoscópico da marca Wild modelo M3Z. Este mesmo equipamento foi utilizado para confecção das ilustrações de morfologia externa, e os desenhos de genitália foram feitos com o auxílio de um microscópio óptico Zeiss, ambos acoplados com câmara clara. O tipo foi fotografado em vista dorsal e lateral, utilizando-se um computador com software de automontagem, conectado a um microscópio estereoscópico Wild M400 com câmera digital JVC KY-F70 acoplada.

A terminologia adotada segue principalmente os trabalhos de Kramer $(1964)$ e Young $(1968,1977,1986)$, exceto para as estruturas da cabeça, cuja terminologia segue o trabalho de Hamilton (1981), conforme sugerido por Mejdalani (1998); a venação das asas segue CoMsTock \& NeEDHAM $(1898,1899)$, como sugerido por Triplehorn \& Johnson (2005) e OMAN (1949), e a posição das cerdas da tíbia posterior segue Rakitov (1998). As medidas são fornecidas em milímetros.

\section{Neocoelindroma gen. nov.}

Espécie-tipo: Neocoelindroma nigricephala sp. nov.

Diagnose. Sutura coronal longa e evidente, quase atingindo a margem anterior da coroa (Fig. 1); carena presente entre coroa e fronte; venação da asa anterior indistinta, exceto sutura claval e células apicais (Fig. 4); asa posterior com veias $\mathrm{R}_{4+5}$ e $\mathrm{M}_{1+2}$ convergentes pré-apicalmente, fusionadas no ápice; genitália masculina: pigóforo sem processos, com dente ventral no terço apical (Fig. 5); edeago longo e sem processos (Fig. 9); tubo anal com par de processos basais (Figs 5 e 10).

Descrição. Em vista dorsal, corpo aproximadamente cilíndrico, estreitado, não achatado dorso-ventralmente.

Cabeça. Em vista dorsal, com coroa aproximadamente pentagonal, pouco projetada anteriormente, tão larga quanto longa (Fig. 1); margem anterior arqueada e angulada, com carena na transição entre coroa e fronte; margens laterais, adjacentes aos olhos compostos, elevadas e fortemente carenadas (Fig. 2); superfície côncava e com leves estrias longitudinais; máculas coronais bem visíveis; sutura coronal bem evidente, estendendo-se por quase todo comprimento da coroa, da base até próximo ao ápice (Fig. 1); ocelos pequenos, na margem anterior da cabeça, na transição entre coroa e fronte, logo abaixo da carena de separação, mais próximos aos olhos compostos que da linha mediana, não visíveis em vista dorsal; lobos supra-antenais, em vista lateral, oblíquos e fortemente carenados; flagelos antenais mais longos que a metade basal das asas anteriores; fronte com comprimento aproximadamente igual à sua largura basal, perfil convexo e textura finamente pontuada, com intumescimento central na base, carenada em toda metade basal; impressões musculares indistintas; suturas frontogenais atingindo os ocelos; margem apical da maxila ultrapassando o ápice do clípeo; loros aproximadamente semilunares, margens inferiores não atingindo o ápice do clípeo; genas não cobrindo completamente os proepisternos, estes visíveis em vista frontal apenas pelo ápice (Fig. 3); sutura epistomal distinta e completa, retilínea; clípeo retangular, com margens laterais paralelas e margem apical retilínea, em vista lateral, não intumescido (Figs 2-3).

Tórax. Pronoto pouco mais largo que a cabeça, margens laterais arredondadas, margem posterior emarginada (Fig. 1); superfície com estrias transversais; carena dorsopleural completa (Fig. 2); mesotórax, em vista ventral, moderadamente intumescido; escutelo (sensu Young 1968) tão longo quanto sua largura máxima, com sulco distinto pré-apical. Asa anterior aproximadamente quatro vezes mais longa que sua largura máxima; com ápice arredondado; sem pontuações; venação indistinta, exceto pela sutura claval e células apicais; quatro células apicais, quarta célula apical pouco visível; todas células apicais aproximadamente retangulares; terceira e quarta células apicais alargadas apicalmente; células anteapicais indistintas; apêndice estreito, estendendo-se ao longo da primeira e segunda células apicais (Fig. 4). Asa posterior com três células apicais, $\mathrm{R}_{4+5}$ e $\mathrm{M}_{1+2}$ convergentes pré-apicalmente, fusionandose no ápice. Perna posterior: fileira PD da tíbia com cerdas longas e grossas, sem cerdas intercalares, uniformemente distribuídas por todo comprimento da tíbia; fileira $\mathrm{AD}$ com cerdas longas, espiniformes, mais engrossadas que as de $\mathrm{PD}$, com bases levemente proeminentes, distribuídas por todo comprimento da tíbia e com duas ou mais cerdas curtas intercalares; fileira AV com apenas duas cerdas curtas, afastadas entre si, no terço apical da tíbia, sem cerdas nos terços basal e médio; fileira PV densamente cerdosa, com cerdas curtas na base, crescentes em tamanho em direção ao ápice, distribuídas em todo comprimento da tíbia; tarsômero basal tão longo quanto o comprimento da soma dos dois mais distais, com duas fileiras paralelas de microcerdas na superfície plantar.

Genitália masculina. Pigóforo sem processos, com dente ventral no terço apical (Fig. 5); valva subgenital fusionada às placas subgenitais; placas subgenitais fusionadas por quase todo seu comprimento, exceto no ápice (Fig. 6); estilos simples, não bifurcados, com ápice em forma de gancho esclerosado, curvado ventralmente (Figs 7-8); conetivo em forma de "V" (Fig. 8); edeago longo e sem processos (Fig. 9); tubo anal com par de processos basais (Figs 5 e 10).

Comprimento total (corpo + asas anteriores): 5,0-6,0.

Distribuição geográfica. Equador.

Comentários. Pela chave dicotômica de Kramer (1964), Neocoelindroma gen. nov. seria identificado como Coelindroma. Assemelha-se a este gênero pela presença de mancha preta no 

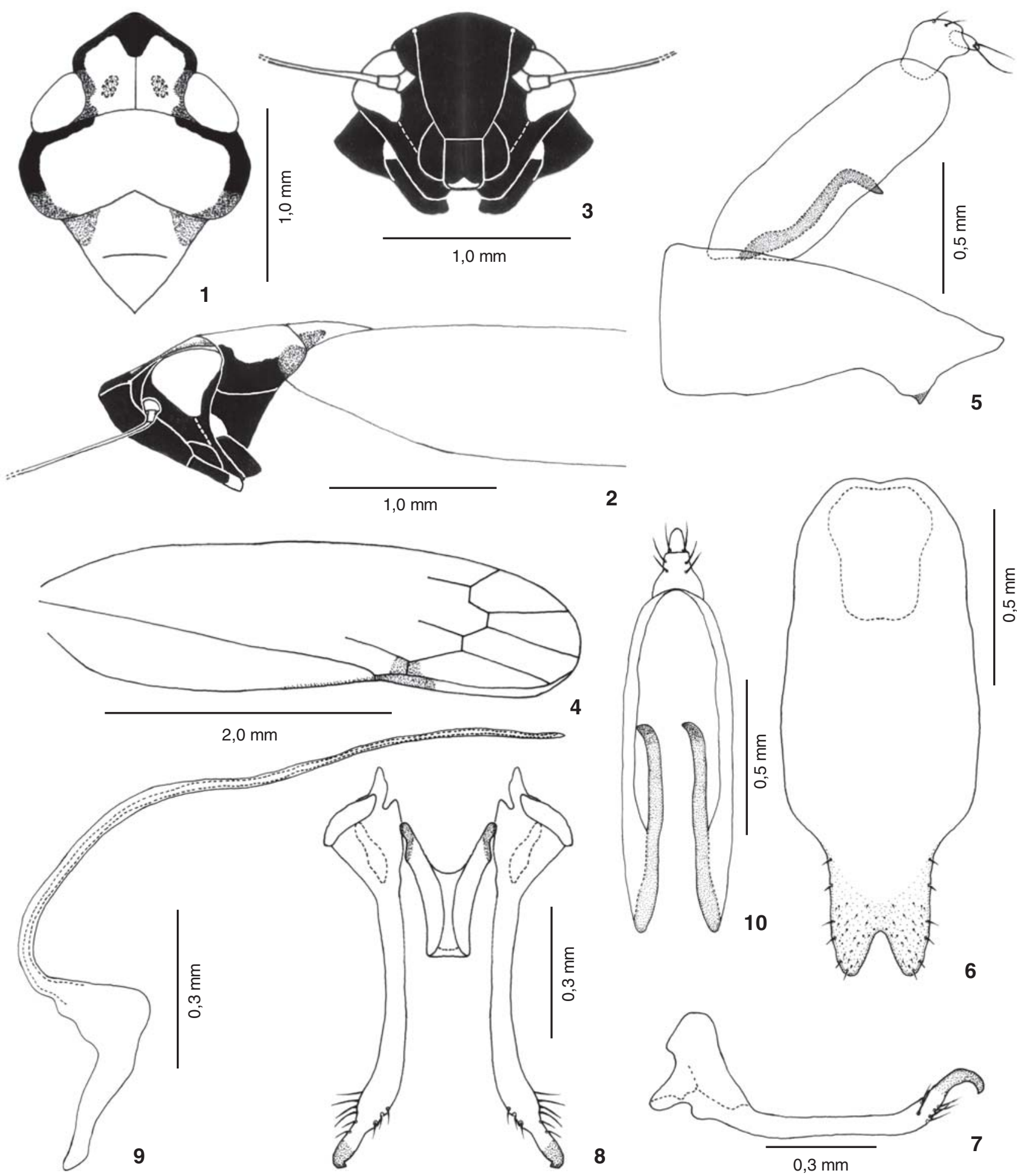

2

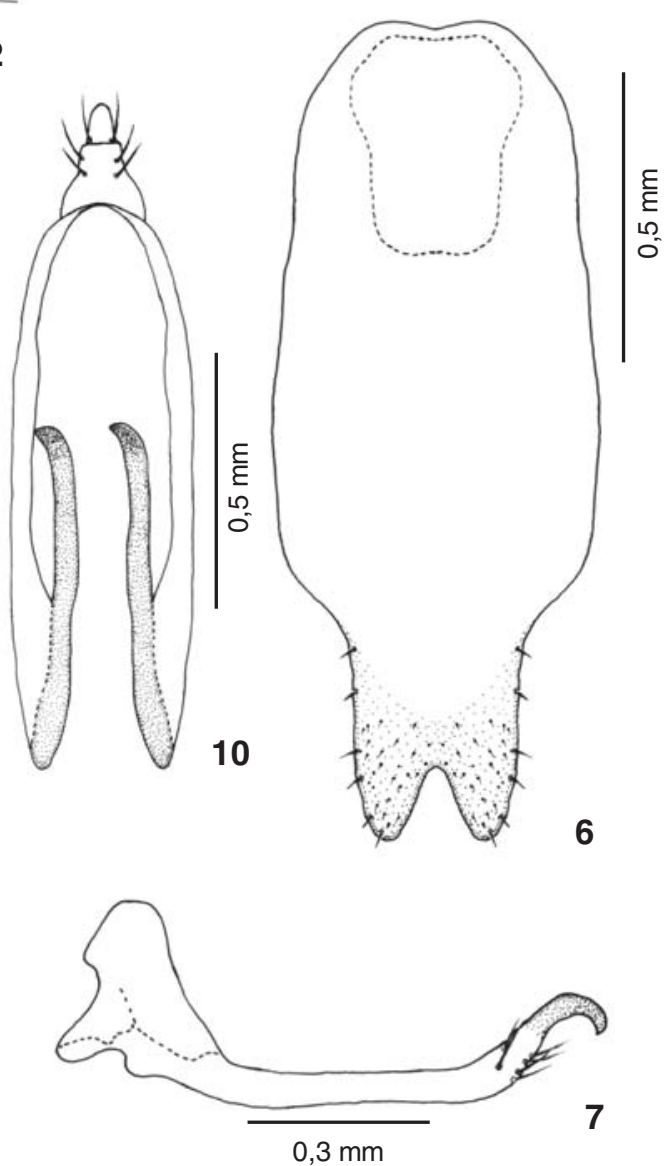

8

Figuras 1-10, Neocoelindroma nigricephala sp. nov., holótipo macho: (1) cabeça, pronoto e escutelo, vista dorsal; (2) cabeça, pronoto e escutelo, vista lateral; (3) cabeça, vista frontal; (4) asa anterior; (5) pigóforo e tubo anal, vista lateral; (6) placas subgenitais, vista ventral; (7) estilo, vista lateral; (8) estilos e conetivo, vista dorsal; (9) edeago, vista lateral; 10, tubo anal, vista ventral. 
ápice da coroa (Fig. 1), pela ausência de processos no pigóforo (Fig. 5), pelo formato alongado do edeago (Fig. 9) (muito mais alongado em Neocoelindroma gen. nov. que em Coelindroma) e pela venação indistinta das asas anteriores (Fig. 4). Entretanto, pode ser separado deste e dos demais gêneros pelo seguinte conjunto de características: sutura coronal longa e evidente (Fig. 1); pigóforo sem processos, com dente ventral no terço apical (Fig. 5); placas subgenitais fusionadas em quase todo seu comprimento, exceto no ápice (Fig. 6); edeago longo e sem processos (Fig. 9), e tubo anal com par de processos basais (Figs 5 e 10).

Etimologia. O nome do gênero é feminino e combina a palavra neos, do grego = novo, com o nome do gênero ao qual se assemelha, Coelindroma.

\section{Neocoelindroma nigricephala sp. nov. Figs 1-12}

Localidade-tipo: Estácion Biológica Jatun Sacha, Napo, Equador.

Diagnose. Coroa com grande mancha apical marrom-escura a preta; cabeça, em vista frontal, quase que inteiramente preta; pigóforo, em vista lateral, aproximadamente triangular (Fig. 5); placas subgenitais fortemente estreitadas no quarto apical (Fig. 6); edeago com haste extremamente fina e longa (Fig. 9); tubo anal membranoso e engrossado, com par de processos basais longos e esclerosados, de ápices curvados para a esquerda (Figs 5 e 10).

Medidas. Holótipo macho: comprimento total 5,05; comprimento mediano da coroa 0,52 ; distância transocular 1,20; distância interocular 0,60; comprimento mediano do pronoto 0,48; distância trans-humeral 1,36; comprimento mediano do escutelo 0,80; largura máxima do escutelo 0,80; comprimento da asa anterior 4,0; largura máxima da asa anterior 1,0; largura basal da fronte 0,48 ; comprimento da fronte 0,64 .

Descrição. Caracteres estruturais como na descrição genérica. Comprimento mediano da coroa aproximadamente igual à distância interocular e aproximadamente metade da distância transocular; fronte com comprimento aproximadamente igual à sua largura basal; distância trans-humeral aproximadamente igual à distância transocular e comprimento mediano do pronoto aproximadamente um terço da distância trans-humeral; asa anterior com comprimento aproximadamente quatro vezes sua largura máxima, terceira célula apical distal em relação à base da asa, se comparada com as segunda e quarta células apicais, as últimas aproximadamente eqüidistantes da base; fórmula femoral posterior $2+2+1$. Genitália masculina: pigóforo, em vista lateral, aproximadamente triangular, com base alargada, estreitando-se gradativamente em direção ao ápice, ápice estreitado e angulado, sem cerdas (Fig. 5). Placas subgenitais aproximadamente quadrangulares, estreitadas e com microcerdas somente no quarto apical; ápices arredondados; tão longas quanto o pigóforo; cada placa com comprimento aproximadamente cinco vezes sua largura máxima (Fig. 6); em vista lateral, sem dentes e com ápice não curvado para cima. Estilos longos e afilados, com cerdas na por- ção pré-apical e margens sem ondulações (Figs 7-8). Conetivo com ramo central alargado, cerca de um terço do comprimento dos estilos, articulado à base do edeago (Fig. 8). Edeago, em vista lateral, com base alargada e prolongamento basal estreitado através do qual se liga ao conetivo; haste simples, extremamente fina e longa, recurvada anteriormente e dorsalmente; margem ventral do edeago lisa, sem dentes; gonóporo apical (Fig. 9). Tubo anal membranoso e engrossado, com par de processos basais longos e esclerosados, com ápices curvados para a esquerda (Figs 5 e 10$)$.

Fêmea. Desconhecida.

Coloração geral. Amarelo-pálida a esbranquiçada com manchas marrom-escuras a pretas. Cabeça, em vista frontal, quase que inteiramente preta, brilhante, exceto ápice do clípeo e antenas, amarelo-pálidos (Fig. 3). Coroa amarelo-pálida, com margens laterais, adjacentes aos olhos compostos, marrom-escuras a pretas e grande mancha central preta no ápice da coroa, unida às manchas laterais; máculas coronais manchadas de marrom-claro (Fig. 1). Pronoto esbranquiçado com margens laterais marrom-escuras a pretas (Fig. 1); proepisterno amarelo-pálido e proepímero preto (Figs 2-3); pleura, porção ventral do tórax, terço basal dos fêmures anteriores e coxas médias pretos (Fig. 2). Escutelo esbranquiçado com um par de manchas aproximadamente triangulares marrom-escuras junto aos ângulos laterais (Fig. 1). Asa anterior hialina, sem coloração distinta, com veias incolores e duas pequenas manchas castanho-claras quase inconspícuas: uma na margem anal, próxima ao ápice do clavo, e outra na base da primeira célula apical e apêndice; terceira e quarta células apicais levemente castanhas (Fig. 4). Asa posterior hialina com veias incolores. Pernas amareladas com cerdas amarelas a castanhas.

Distribuição geográfica. Equador.

Material examinado. Holótipo macho (USNM): "ECUADOR, Napo, Estácion Biológica Jatun Sacha, 02.viii.1989, at light, Paul Freytag and T. Myers leg."

Condição do holótipo. Tórax colado ventralmente em triângulo entomológico; flagelos antenais quebrados apenas no terço apical; pernas inteiras, as anteriores e médias coladas no triângulo; asas anteriores e posteriores em perfeito estado de conservação, porém parcialmente cobertas por escamas de Lepidoptera, fortemente aderidas às asas, cuja remoção não foi possível; abdome dissecado.

Etimologia. Do latim, nigri $=$ preto, negro + cephalum $=$ cabeça, daí o nome nigricephala, referindo-se à coloração da cabeça, quase inteiramente preta, em vista frontal.

\section{AGRADECIMENTOS}

A Paul H. Freytag (University of Kentucky, Estados Unidos) pelo empréstimo do espécime. A Thomas J. Henry e à Michele A. Touchet (técnica do setor de Entomologia) pela orientação e auxílio durante o estágio de Doutorado Sanduíche realizado no USNM. À Coordenação de Aperfeiçoamento de Pessoal de Nível Superior (CAPES) pela bolsa de Doutorado San- 


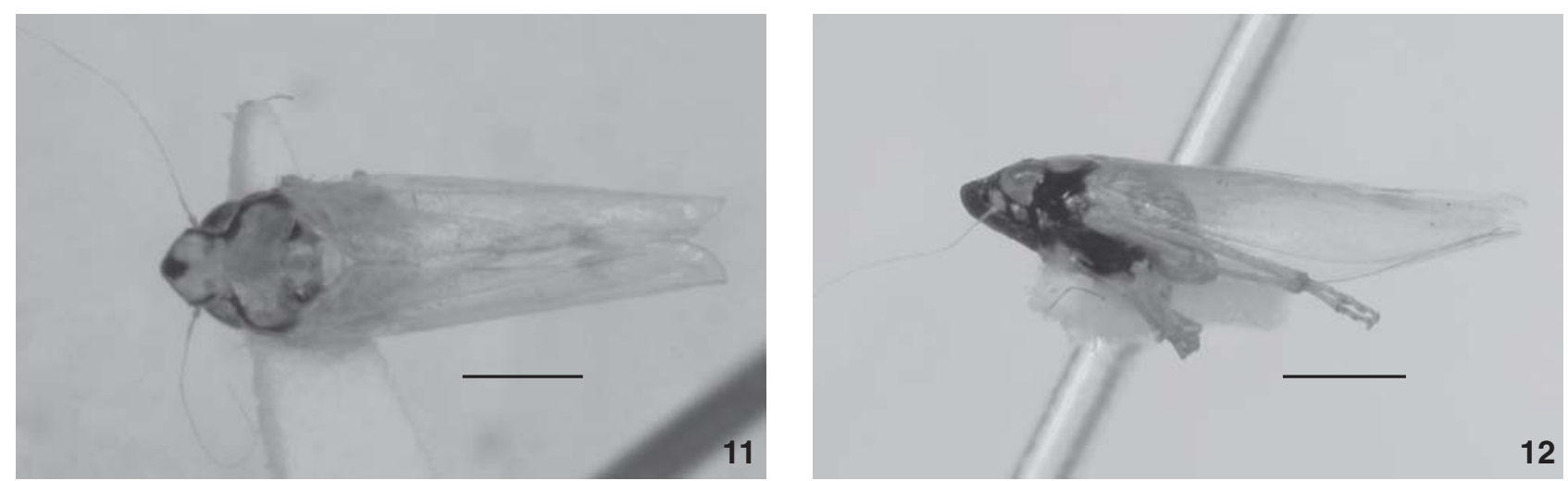

Figuras 11-12. Neocoelindroma nigricephala sp. nov., holótipo macho: (11) vista dorsal; (12) vista lateral. Escala = 1,0 mm.

duíche concedida à primeira autora e ao Conselho Nacional de Desenvolvimento Científico e Tecnológico (CNPq) pela bolsa de produtividade concedida ao segundo autor.

\section{REFERÊNCIAS BIBLIOGRÁFICAS}

Comstock, J.H. \& J.G. Needham. 1898. The wings of insects. American Naturalist 32: 43-48, 81-89, 231-257, 335-340, 413424, 561-565, 768-777, 903-911.

Comstock, J.H. \& J.G. Needham. 1899. The wings of insects. American Naturalist 33: 117-126, 573-582, 845-860.

Dietirch, C.H. 2003. Some unusual neotropical Neocoelidiinae with a redefinition of the subfamily (Hemiptera: Membracoidea: Cicadellidae). Annals of the Entomological Society of America 96 (6): 700-715.

Dietirch, C.H. 2004. Phylogeny of the leafhopper subfamily Evacanthinae with a review of neotropical species and notes on related groups (Hemiptera: Membracoidea: Cicadellidae). Systematic Entomology 29: 455-487.

Hamilton, K.G.A. 1981. Morphology and evolution of the rhynchotan head (Insecta: Hemiptera, Homoptera). Canadian Entomologist 113: 953-974.

KRAMER, J.P. 1964. A generic revision of the leafhopper subfamily Neocoelidiinae (Homoptera: Cicadellidae). Proceedings of the United States National Museum 115: 259-287.

Marques-Costa, A.P. \& R.R. Cavichioli. 2006a. Revisão taxonômica, análise cladística e descrição de espécies novas de Aglaenita Spinola (Hemiptera, Cicadellidae, Neocoelidiinae). Revista Brasileira de Entomologia 50: 355-378.

Marques-Costa, A.P. \& R.R. Cavichioli. 2006b. A new genus of
Neocoelidiinae Oman (Hemiptera: Auchenorrhyncha: Cicadellidae). Zootaxa 1361: 45-51.

Mejdalani, G. 1998. Morfologia externa dos Cicadellinae (Homoptera: Cicadellidae): comparação entre Versigonalia ruficauda (Walker) (Cicadellini) e Tretogonia cribrata (Melichar) (Proconiini), com notas sobre outras espécies e análise da terminologia. Revista Brasileira de Zoologia 15: 451-544.

Nielson, M.W. \& W.J. Knight. 2000. Distributional patterns and possible origin of leafhoppers. (Homoptera, Cicadellidae). Revista Brasileira de Zoologia 17: 81-156.

Oman, P.W. 1949. The Nearctic leafhoppers (Homoptera: Cicadellidae). A generic classification and check list. Memoirs of the Entomological Society of Washington 3: 1-253.

RAKITOV, R.A. 1998. On differentiation of cicadellid leg chaetotaxy. Russian Entomological Journal 6: 7-27.

Triplehorn, C.A. \& N.F. Johnson. 2005. Borror and DeLong's Introduction to the Study of Insects. Belmont, Thomson Brooks/Cole, $7^{\text {th }}$ ed., $864 \mathrm{p}$.

Young, D.A. 1968. Taxonomic study of the Cicadellinae (Homoptera, Cicadellidae). Part 1. Proconiini. Bulletin of the United States National Museum 261: 1-287.

Young, D.A. 1977. Taxonomic study of the Cicadellinae (Homoptera: Cicadellidae). Part 2. New World Cicadellini and the genus Cicadella. Bulletin of the North Carolina Agricultural Experiment Station 239: VI+1135p.

Young, D.A. 1986. Taxonomic study of the Cicadellinae (Homoptera: Cicadellidae). Part 3. Old World Cicadellini. Bulletin of the North Carolina Agricultural Experiment Station 281: 1-639.

Recebido em 30.XI.2006; aceito em 07.III.2007. 